DOI: 10.1515/linpo-2015-0009

\title{
Megametaphor as a coherence and cohesion device in a cycle of literary texts
}

\author{
Zoya Rezanova $^{1,2}$ \& Konstantin Shilyaev ${ }^{1}$ \\ ${ }^{1}$ Department of General, Slavic-Russian Linguistics and Classical Philology, Tomsk State Univer- \\ sity, Tomsk \\ ${ }^{2}$ Department of Russian as a Foreign Language, Tomsk Polytechnic University, Tomsk \\ rezanovazi@mail.ru,shilyaevc@gmail.com
}

\begin{abstract}
Zoya Rezanova \& Konstantin Shilyaev. Megametaphor as a coherence and cohesion device in a cycle of literary texts. The Poznan Society for the Advancement of Arts and Sciences, PL ISSN 0079-4740, pp. 31-39

The present study is concerned with the notion of megametaphor and its role in the cohesion and coherence of the text, as well as its intertextual function. We discuss the method of identifying and structuring megametaphor in a literary text and apply it to four novels by Jack London that have dogs as their protagonists. The megametaphor DOG IS A MAN is shown to organize the texts both conceptually - via a coherent set of frame structures of the source domain - and linguistically, by way of applying a network of metaphorical lexemes to the description of a dog.
\end{abstract}

Keywords: megametaphor, conceptual metaphor theory, cohesion, coherence, J. London

\section{Introduction}

The notion of megametaphor (also known as extended metaphor, sustained metaphor) has been treated in various publications, among which the most known are, perhaps, Werth 1994, Steen \& Semino 2008 and Kovecses 2010. Megametahor is commonly viewed as a conceptual device that provides coherence for micrometaphors - its linguistic manifestations in the text or discourse. However, not much work has centred on its application to large bodies of text or novel cycles. The present study focuses on the way a megametaphor functions as both a cognitive and linguistic mechanism that grants coherence and cohesion to the text in a cycle of novels by Jack London, namely, those that portray the life of a dog: "The Call of the Wild" (1903), "White Fang" (1905), "Jerry of the Islands" and "Michael, Brother of Jerry" (both published posthumously in 1917). 


\section{Theoretical foundations}

The present work is based on two areas of linguistic inquiry: theory of text (discourse) and Conceptual Metaphor Theory (CMT) in its present state as outlined in Lakoff 2008. We also rely on Frame Semantics (Fillmore 2007), in particular, on its methodology of representing and structuring areas of knowledge.

For the purposes of our study, which concerns written works of fiction, we view the text as a product of discourse that has completeness, grammatical, lexical, logical and stylistic connections, and is objectified in written form (Galperin 1981). At the same time we view the text as a particular representation of the knowledge (including background knowledge) of its author (Valgina 2003). These definitions correspond to the two levels of text: the level of linguistic representation (hereafter linguistic or surface level) and the level of cognitive structures (hereafter cognitive level).

Among the various characteristics of the text (cf. Beaugrande \& Dressler 1981; Brown \& Yule 1983; Galperin 1981; Halliday \& Ruqaiya 1986) our study focuses on the two most cited: coherence and cohesion. Coherence refers to the cognitive interconnections that make up the conceptual and content structure of the text. Cohesion is mostly concerned with linguistic relations between the units of the text and its lexical content in particular. The category of intertextuality is also important for the study of the way a megametaphor organizes texts and cycles of texts. We define it as the connection between various texts united by certain conceptual and textual elements.

For the study of metaphor we rely on the main propositions of Conceptual Metaphor Theory. We view metaphor as an important mechanism of the human cognitive system which consists in (partial) mapping of one conceptual domain (source domain) onto another (target domain) as a way of its conceptualization, e.g. THEORIES ARE BUILDING: This theory has a shaky foundation. Systems of conceptual metaphors are posited to exist in various languages of the world. These conceptual metaphors are deemed vital to everyday construal of human experience and are shared by all speakers of a language (Lakoff 2008).

Creative extension of everyday conceptual metaphors in literary works was first studied by G. Lakoff and M. Turner (1989). Their study determined 4 types of metaphorical extension - the ways in which everyday conceptual metaphors are modified and combined to form new artistic meaning. In the following works by P. Werth, G. Steen, E. Semino and Y. Popova the notion of megametaphor was introduced and studied. While (Lakoff \& Turner 1989) was mostly concerned with relatively short stretches of literary language, these subsequent studies embarked on the exploration of poems and novels.

In order to represent the cognitive structure of domains of metaphor we borrow the notion of a predicative frame from Frame Semantics (Fillmore 2007). A predicative frame is a knowledge structure serves to represent a particular situation through a set of its participants (arguments) and relations between them. The classic example is the frame for commercial transaction, which includes the SELLER, BUYER, GOODS and various actions (BUY, SELL, PAY, etc.) that profile different aspects of the situation. 


\section{Materials and methodology}

For the purposes of analysis we use a number of notions. The key notion in the present study is megametaphor (in Russian linguistics usually called key textual metaphor (Rezanova 2007)). We define it as a conceptual metaphor that gives coherence to metaphorical expressions of a particular text, at the same time organizing the text into a coherent whole. As Z. Kovecses notes, it "may run through entire literary texts without necessarily "surfacing"" (Kovecses 2010: 57). We believe that it manifests itself through the metaphorically used lexemes in the text, commonly called "micrometaphors".

In order to specify the mechanism of its manifestation, we introduce the notion of metaphorical models. A metaphorical model is both a cognitive and linguistic unit, which includes source and target domains, their corresponding micrometaphors (in the form of metaphorically used lexical units) and the mappings between them (Figure 1).

We use frame semantics for modelling the structures of both the source and target domains. The slots of the frame structure of the source domain are typically filled with the micrometaphors of the text, thus providing a link between its lexical and conceptual structure. If the target domain is a vague or missing part of human experience there is no matching between two frame structures, but rather the projection of the whole frame structure from the source domain. This is precisely the case of our study, where megametaphor is used to conceptualize various parts of the reality of being a dog. Given that a typical human being has no immediate experience of the way a dog "thinks" or "feels", metaphoric mapping is the only way possible for the author to portray a dog protagonist in a novel.

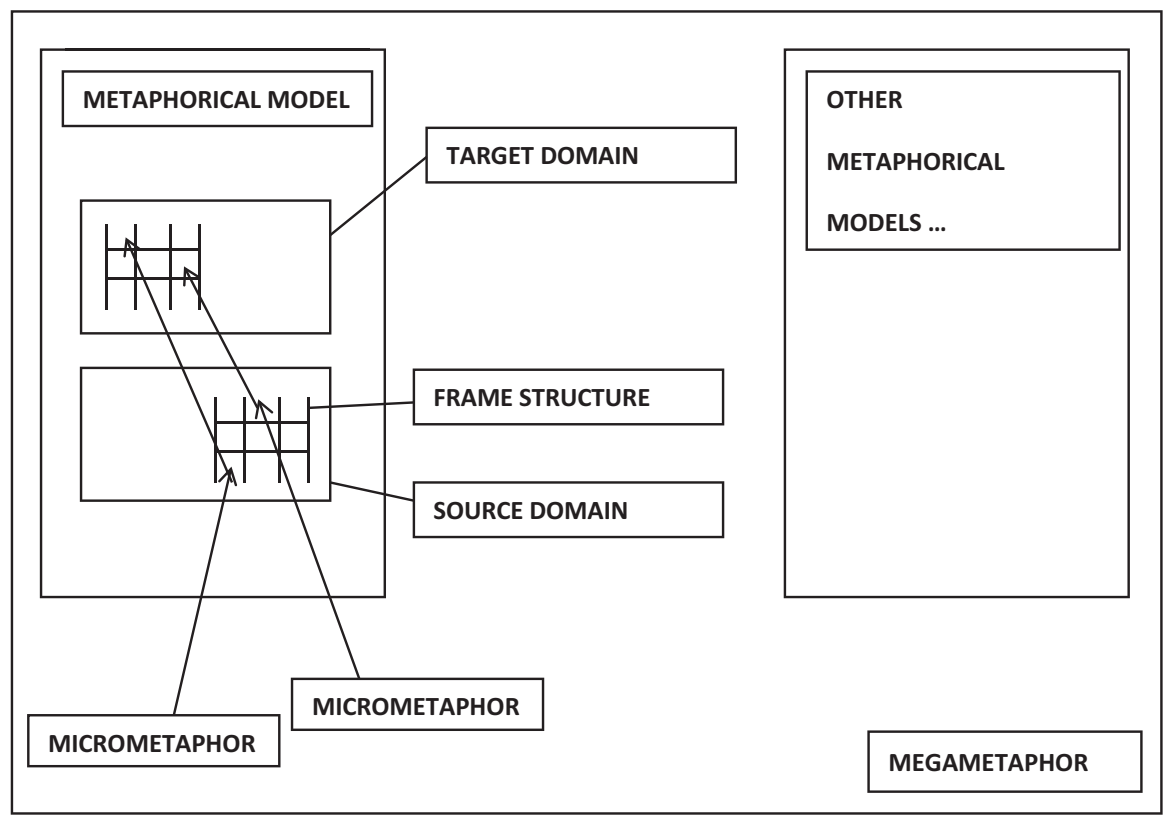

Figure 1: Typical structure of megametaphor 
The identification of micrometaphors in the text is a modified version of MIP outlined in (Steen 2010). We will outline the procedure we followed in detail, at the same time demonstrating the specificity of metaphor identification in the novels that were selected for analysis.

The texts were first read, lexemes highlighted and their contextual meaning defined. Next, the contextual meaning was contrasted against the corresponding entry in Oxford Dictionary of English (2nd ed., 2005) and Oxford Advanced Learner's Dictionary (8th ed., 2010). If in the definition there was found a more concrete and basic meaning (usually related to physical or, at times, social reality), the contextual meaning was considered to be metaphorical. In other words, the lexeme could not be read literally (as opposed to figuratively). To check whether the semantics of the lexeme prevented its literal reading and construal, we used componential and definitional analysis.

For instance, in the next textual fragment (from the novel "Jerry of the Islands"), the communication between Jerry, the Irish terrier, and its master is described in the following way: Practically all their conversation was confined to the instant present. The pronoun their refers both to the man and his dog and can be read literally. However, the noun conversation can not be applied literally to a dog, since it implies the ability to talk, converse. Therefore, the word combination their conversation in the context of the novel was considered a metaphor. The predicate was confined to the instant present is also a metaphor used to characterize the way a dog and its owner "talk". Although the combination conversation was confined to the instant present is not itself a metaphor, it becomes one for the same reason conversation is metaphorical - it characterizes the communication between a dog and a human being, and through this relation is also metaphorical.

Furthermore, not only single lexemes become metaphorical in the texts analyzed, but also whole stretches of text up to several sentences and, occasionally, paragraphs. In the next fragment, J. London describes the dreams and vision of Buck, the protagonist in "The Call of the Wild", which walks with pre-historic men in the other world: The salient thing of this other world seemed fear. When he watched the hairy man sleeping by the fire, head between his knees and hands clasped above, Buck saw that he slept restlessly... This passage (abridged here) is preceded by the sentence The vision of the short-legged hairy man came to him more frequently. Here the dog becomes the metaphorical subject of dreaming ( him, here expressed with the help of a passive construction), the micrometaphor being vision came to him. The passage that describes the other world comes next, and by way of describing the details of the dream becomes a metaphor itself.

After the metaphors had been identified, we arranged them into frame structures on the basis of their relations with three spheres of human knowledge and experience: cognition, emotion and social relationships. Depending on the structure of a particular frame, the micrometaphors were further subdivided into the slots of subject, action or state, object and the slots of their properties. For example, in the case of cognition, the typical micrometaphors that fill the slot of action or state are know, think, understand, consider - all of them are used to denote the mental activity of a dog in the novels that were analyzed. The slot of the subject is by default filled by the dog-protagonist. The objects of dog's cognition are varied: idea, thought, knowledge are among the most frequent. The slot of properties of object in this case is filled with such micrometaphors as clear, precise or vague, which denote the 
qualities of the concepts a dog can have. In the next section a similar frame analysis is given in full detail for the sphere of "will" of the dog-protagonists.

In order to be able to clearly identify metaphors in the specific texts that were analyzed, we elaborated a criterion for classifying linguistic expressions that refer to the dog as a subject of mental, emotional or social activity as metaphors. It is based on Morgan's Canon: "[animal] behavior should be explained with reference to mental processes that stand lower on the scale of evolution and development" (Miklosi 2007: 18-19). The issue of anthropomorphism in the studies of animal behavior is a hotly debated one. It is either rejected and warned against (Kennedy 1992) or partly accepted as a methodological strategy (Walker 1985: 382-388; Dagg 2011: 6). Among the notions that are advised be avoided when describing animal behavior are motivation (Barnard 2004: 195; Kennedy 1992), goal-directedness, intentionality, consciousness, concept of "self" and language (Walker 1987: 333-345). The principal issue with these terms is that they all refer to areas of subjective human experience.

The definitions in the dictionaries used to check the metaphorical status of a word or a sequence of words all make heavy use of human-related notions and concepts. Lexemes that denote cognition, emotion or social interaction are defined relative to a human subject. Therefore, when used with a dog as subject, we will consider them metaphors. This is not to say that a dog cannot "remember" or even "be angry". What is important is that when a reader perceives the text, a construal with reliance on human experience is inevitable, hence the conceptual megametaphor DOG IS A MAN. This is the way dogs are depicted in the novels by J. London. The structure of this metaphor and its role in creating coherence and cohesion in the text are discussed in the next section.

\section{Results and discussion}

By conducting the analysis we have discovered that the megametaphor in the four novels is DOG IS A MAN. By way of this anthropomorphic megametaphor, Jack London maps the domains of human experience onto the life of the dog protagonists portrayed in the novels. The three source domains that have been identified are social relationships, cognition and emotion. These source domains are structured by corresponding frames "social relationships", "cognition" and "emotion". These frames are further subdivided, on the basis of semantic and experiential grouping, into subframes. The whole frame structure and the principal interactions between the frames are outlined in the Figure 2.

The frame structure of the domains was found to have an invariant part and a universal set of lexemes that fill its slots. These lexemes are present in all the texts analyzed.

The frames of the source domains interact on the surface of the text. In the following fragments, taken from the novel "Michael, Brother of Jerry", the relationship of power (master and servant) is metaphorically mapped onto the relationship between the dog and its masters. In the first sentence the dog is a willing servant of its master, glad to offer its services: ... he had the heart that made it a happiness for him to serve. Happiness, a metaphorical lexeme from the frame "emotion", functions here as a property of a metaphorical action, denoted by the lexeme serve. The latter belongs to the subframe "power" of the frame "social relationships". 
In the second sentence, the dog shows its consciousness and free will by choosing its master, and even becomes a subject of power itself by lording it over the servant: Michael, out of love, would serve Steward, but Michael lorded it over the kinky-head. Here, once again, service is accompanied by a positive emotion on the part of the dog. We treat would as a modal verb here, expressing willingness or consent - it belongs to the subframe "will" of the frame "cognition". The resulting interaction of metaphorical lexemes serves to create the metaphorical image of a dog as a conscious subject, capable of experiencing emotion, controlling its urges and engaging in various types of social relationships.

Next we give an example of a part of invariant frame structure and its fillers, namely the subframe "will", which is one of the prime representatives of the way a dog is anthropomorphized in the works of Jack London. The quality of free will and conscious action is traditionally considered one of those that distinguishes the man from the animal, and its metaphorical projection onto the dog makes it a conscious subject.

The following outline is a concise representation of the slots and the lexemes (micrometaphors) that act as their fillers. First we describe the actions that the dog is capable of as a willing agent. Among the fillers of this slot we have included the lexemes (mostly verbs) with the semantics of a conscious, deliberate action and control. Depending on the context, they may denote actions or states.

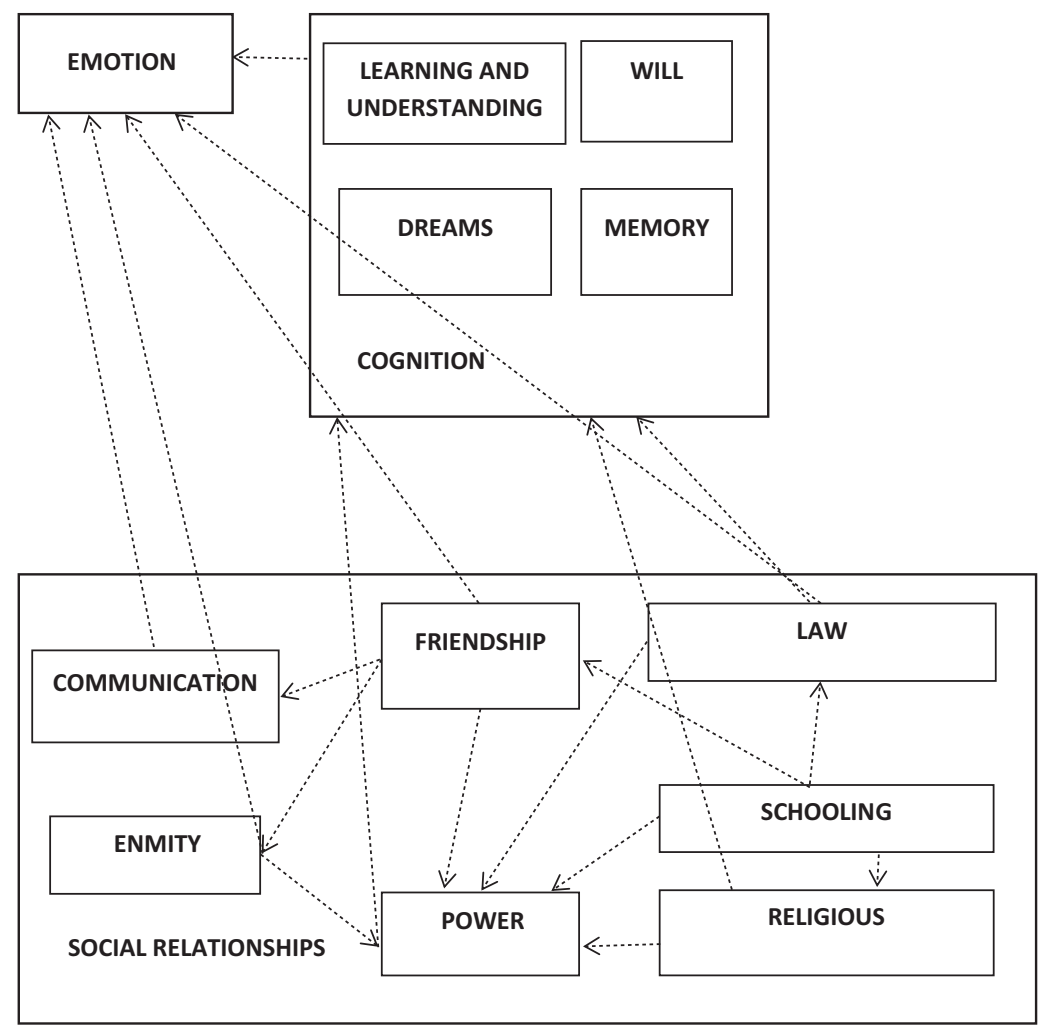

Figure 2: Frame structure of the megametaphor DOG IS A MAN 
Actions or states: accept, attempt, desire, effort, endure, be intent/intention, want, would, yearn, adjust, dare, decide, determine, do one's best, feign, forego, go out of one's way, hesitate, make up one's mind, master, need, refrain, refuse, restrain/restraint, stand, strain, strive, tolerate, try, wont, yield.

The semantics of self-restraint that many of these lexemes have point in the direction of the author's intention: the dog is not only conscious of its volitions, but it is also active in their control, as demonstrated in the next fragment, taken from the novel "White Fang": Meat, even meat itself, he would forego to be with his god, to receive a caress from him or to accompany him down into the town.

The volitions, urges and needs of the dog-protagonists have metaphorical names as well. We have designated them as objects, existing in the space of the dog's mind, since the widely documented conceptual metaphor MIND IS A CONTAINER is applied to the contents of the dog's mind and motivates much of its metaphorical depiction.

Objects: desire, impulse, instinct.

The dog, as portrayed by Jack London, is capable of accepting or rejecting the prod of its instincts, thus determining its own conduct, as is shown in the next fragment, also taken from the novel "White Fang": For him to attack her would require nothing less than a violation of his instinct. Very often in the actual text the object of control and suppression on the part of the dog is an emotion, such as anger, rage and similar ones. This as also a manifestation of interaction between frames of source domains, namely, the subframe "will" and the frame "emotion".

Being a conscious subject, the dog protagonist has its own metaphorically mapped properties related to the sphere of will: control, will; poise, cold/cold-blooded. These properties are essential to its proper functioning in the world of men-gods and dogs that is governed by a system of laws to which every dog must submit (the fragment is taken from "Jerry of the Islands"): But with a superior, with a two-legged white-god like Borckman, there was more a demand upon his control, restraint, and inhibition of primitive promptings. Here a complex interplay of metaphorical domains is evident in the micrometaphors: the dog submits itself to the power (superior, the subframe "power") of its human master, whom it worships (two-legged white god, the subframe "religious relationships"). In order to be a proper participant in the social relationships with a superior human, it must exhibit control (subframe "will") so as not to violate the explicit and implicit laws set up by its human masters (subframe "law").

The frequent interaction between the frames of the source domains social relationships and cognition results in a number of metaphorical lexemes that regularly present themselves in the text and denote the properties of the dog's actions in their relation to its will: deliberate/deliberateness, eager/eagerness, earnest/earnestness, involuntarily, un/willingly, blind, careful, cool/coolly, purpose. In the following fragment, borrowed from the novel "The Call of the Wild", the dog performs a deliberate action in the spheres of law and power: $\mathrm{He}$ openly threatened the other's leadership. He came between him and the shirks he should have punished. And he did it deliberately.

The remaining frames and subframes function in a similar way - almost every sentence in the novels analyzed reveals the intricate structuring of source domains that is projected 
onto the target domains. ${ }^{1}$ This projection, reflected in the micrometaphors of the texts, depicts the life of a dog by metaphorically liking it to the life of a human being.

The author employs the same megametaphor in 4 large novels, which results in metaphoric descriptions of dogs that are similar in its core - the essential properties of the dog as a subject of emotion, mental action and social relationships. Thus, megametaphor is also a mechanism of intertextuality.

\section{Conclusion}

The analysis has revealed that megametaphor functions both as a coherence and cohesion device and an intertextual device. We believe to have uncovered the cognitive structures behind the text production - the frame structures of source domains under the overarching megametaphor DOG IS A MAN. The latter unites and gives coherence to the micrometaphors on the surface level of the text.

The interaction between the frame structures of the source domains of megametaphor DOG IS A MAN reflects the interaction of emotional, mental and social components in human experience and grants the text conceptual coherence. In other words, the texts where megametaphor is found are coherent because the frame structures of source domains are coherent in human experience.

The innovation of the author consists in the expansion of everyday conceptual anthropomorphic metaphor into a creative literary megametaphor which is used to depict the thoughts, emotion and interactions of his dog-protagonists. This is done both by expansion of more conventional source domains such as emotion or mental activity and by drawing new spheres of human experience into metaphorical projection, such as religious relationships. Due to the creative genius of the writer this expansion is made in such a way so as not to seem extremely unusual or unnatural.

Textual coherence, being primarily a cognitive category, is expressed in the cohesion of the text on the surface level. The frame structure of source domains manifests itself in a network of lexemes and their associates, which are semantically interconnected and express the notions that constitute the frames. The interaction between the frame structures and their constitutive slots is manifested though a vast array of micrometaphors. The lexemes that constitute these micrometaphors linguistically provide the literary texts we have analyzed with cohesion. However, since cohesion is also is a grammatical category, further research is needed in order give a more detailed outline of the grammatical dimension of megametaphor

\section{Acknowledgements}

This research was supported by Tomsk State University Academic D.I. Mendeleev Fund Program in 2015 (research grant № 8.1.37.2015). 


\section{References}

Barnard, Chris. 2004. Animal Behavior: mechanism, development, function, and evolution. New Jersey: Pearson Education Limited.

Beaugrande, Robert \& Dressler, Wolfgang. 1981. Introduction to Text Linguistics. London-New York: Longman. Brown, Gillian \& Yule, George. 1983. Discourse Analysis. Cambridge: Cambridge University Press.

Dagg, Anne. 2011. Animal Friendships. Cambridge: Cambridge University Press.

Fillmore, Charles. 2007. Frame Semantics. In Evans, Vyvyan (ed.), The Cognitive Linguistics Reader, 238-262. Equinox Publishing Ltd.

Galperin, Iliya. 1981. Tekst kak ob'ekt lingvisticheskogo issledovaniya (Text as the object of linguistic study). Moscow: Nauka.

Halliday, Michael A. K. \& Ruqaiya, Hasan. 1986. Cohesion in English. London: Longman.

Kennedy, John. 1992. The New Anthropomorphism. New York: Cambridge University Press.

Kovecses, Zoltan. 2010. Metaphor - A Practical Introduction. 2nd ed. Oxford: Oxford University Press.

Lakoff, George. 2008. The neural theory of metaphor. In Gibbs, Raymond (ed.), The Cambridge Handbook of Metaphor and Thought, 17-38. Cambridge: Cambridge University Press.

Lakoff, George \& Turner, Mark. 1989. More than Cool Reason: A field guide to poetic metaphor. Chicago: The University of Chicago Press.

Miklosi, Adam. 2007. Dog Behavior: Evolution and Cognition. Oxford: Oxford University Press.

Rezanova, Zoya. 2007. Metaforicheskoe kognitivno-yazykovoe modelirovanie: k probleme mezh'yazykovogo i mezhdiskursivnogo dialoga (Cognitive linguistic modelling of metaphor: the problem of interlingual and interdiscursive dialog). In Evroaziatskiy kul turnyy dialog: "Svoe" $i$ "chuzhoe" v natsional'nom samosoznanii kul'tury. Tomsk: Izd-vo Tom. Un-ta.

Shilyaev, Konstantin. 2014. Osobennosti klyuchevoy tekstovoy metafory v romane Dzh. Londona "Jerry of the Islands" i ego perevode "Dzherri-ostrovityanin" (Distinctive features of the key textual metaphor in the novel Jerry Of The Islands by J. London and its translation into Russian). Tomsk State University Journal 379: 40-45.

Steen, Gerard. 2010. A method for linguistic metaphor identification: from MIP to MIPVU. John Benjamins B. V. Steen, Gerard \& Semino, Elena. 2008. Metaphor in literature. In Gibbs, Raymond (ed.), The Cambridge Handbook of Metaphor and Thought, 232-246. Cambridge: Cambridge University Press.

Valgina, Nina. 2003. Teoriya teksta (Theory of text). Moscow: Logos.

Walker, Stephen. 1987. Animal Behaviour. An Introduction. London: Routledge.

Walker, Stephen. 1985. Animal Thoughts. London: Routledge \& Kenan.

Werth, Paul. 1994. Extended metaphor - a text-world account. Language and Literature 3. 79-103. 
